\title{
Perilaku Hulun (Karma Ning Hulun) dalam Naskah Sanghyang Siksa Kandang Karesian
}

\author{
Erni Siti Nuraeni, Yeni Wijayanti, Dewi Ratih \\ ernisitinuraeni477@gmail.com \\ Universitas Galuh Ciamis
}

\begin{abstract}
The purpose of this research is to dig up the contents of sanghyang siksa kandang karesian manuscript and examine the behavior of hulun (KarmaNing Hulun)against the king in the Country. The method used is a qualitative approach with historical methods or historical methods consisting of heuristics, criticisms, interpretations, and historiography. The results of this study explain that the contents of the manuscript include the rules on Pre-Devotional Watersheds E CretanWatersheds,people's behavior (Karma Ning Hulun)towards the king in the State and complementary deeds(Pangimbuh Ning Twah). The behavior of the people in the script sanghyang Siksa Kandang Karesian is divided into several behaviors including behavior facing the king, good behavior for the crowd, behavior in the presence of menak, behavior of holding secrets, behavior of the people who are disloyal, when seeing people get praise, behavior when elected as a force, getting orders, behavior according tohaan, behavior of walking in theforest, behavior of meeting State officials, behavior of getting ordered to work in the field, when urinating, when sedating the way, when entering the palace, behavior scolded by the king, exemplary behavior that is enviable, behavior after carrying out obligations, behavior gets praise, behavior when resmped, and behavior when getting happiness. Behavioral conclusions in the public are formed from their life habits.
\end{abstract}

Keywords :Behavior, Hulun, Sanghyang Siksa Karesian Cage.

\begin{abstract}
Abstrak
Tujuan penelitian ini untuk menggali isi naskah Sanghyang Siksa Kandang Karesian dan mengkaji perilaku hulun (Karma Ning Hulun) terhadap raja di dalan Negara. Metode yang digunakan yaitu pendekatan kualitatif dengan metode historis atau metode sejarah yang terdiri dari heuristik, kritik, interpretasi, dan historiografi. Hasil penelitian ini menjelaskan bahwa isi naskah mencakup aturan tentang Dasa Prebakti \& Dasa Kreta, perilaku rakyat (Karma Ning Hulun) terhadap raja di dalam Negara dan pelengkap perbuatan (Pangimbuh Ning Twah). Perilaku rakyat dalam naskah Sanghyang Siksa Kandang Karesian terbagi menjadi beberapa perilaku antara lain perilaku menghadap raja, perilaku yang baik bagi orang banyak, perilaku di hadapan menak, perilaku memegang rahasia, perilaku hulun (rakyat) yang tidak setia, ketika melihat orang mendapat pujian, perilaku ketika terpilih menjadi pasukan, mendapat perintah, perilaku menuruti tohaan, perilaku berjalan di hutan, perilaku bertemu pejabat Negara, perilaku mendapat perintah bekerja di ladang, ketika buang air, ketika memintas jalan, ketika masuk keraton, perilaku dimarahi raja, perilaku teladan yang patut ditiru, perilaku setelah melaksanakan kewajiban, perilaku mendapat
\end{abstract}


pujian, perilaku ketika dicela, dan perilaku ketika mendapat kebahagiaan. Kesimpulan perilaku pada masyarkat terbentuk dari kebiasaan kehidupan mereka.

Kata Kunci: Perilaku, Hulun, Sanghyang Siksa Kandang Karesian.

\begin{tabular}{|c|c|}
\hline (c) (i) (?) & $\begin{array}{l}\text { This work is licensed under the Creative Commons Attribution-ShareAlike } 4.0 \\
\text { International License }\end{array}$ \\
\hline
\end{tabular}

\section{Pendahuluan}

Perilaku rakyat di Indonesia diatur dalam Undang-Undang Dasar 1945, pasal 27 ayat (1-3) dan pasal 30 ayat 1 yang menjelaskan setiap warga negara memiliki kewajiban yang harus dilaksanakan terhadap negara. Setiap daerah di Indonesia memiliki aturan budaya yang berbeda antara suku dengan yang lainnya. Dari sekian banyak suku yang ada di Indonesia, salah satunya adalah suku sunda. Sebagai salah satu suku asli dari Indonesia yang memiliki kebudayaan khas. Kebudayaan Sunda merupakan budaya yang berpengaruh bagi perkembangan budaya Indonesia. Sunda sedikit banyak memiliki pengaruh pada perkembangan budaya di Indonesia, terutama pada masa kerajaannya (Pien Supinah, 2006; Dasrun Hidayat \& Hanny Hafiar, 2019). Wujud dari kebudayaan diantaranya adalah adanya naskah-naskah kuno (manuskrip). Naskah kuno merupakan hasil budaya suatu bangsa yang peninggalannya berupa tulisan. Naskah-naskah di nusantara mengemban isi yang beraneka ragam dalam berbagai asepek kehidupan antara lain masalah sosial, politik, ekonomi, agama, kebudayaan, bahasa dan sastra (Baried et al., 1985; Departemen Pendidikan dan Kebudayaan Pusat Penelitian Sejarah dan Budaya; 1990).

Naskah kuno di berbagai daerah Indonesia memiliki fungsi kultural dalam masyarakat. Bahan yang digunakan untuk penulisan naskah kuno yaitu bambu daluang, daun lontar dan ditulis tangan menggunakan aksara Sunda, sansakerta, dan sebagainya. Ditinjau dari wujudnya, naskah-naskah kuno tersebut adalah benda budaya yang berupa hasil karya berupa tulisan tangan yang memiliki makna tertentu, mengandung ide-ide, gagasan, serta berbagai macam pengetahuan tentang alam semesta menurut persepsi budaya masyarakat di berbagai daerah (Karlina et al., 1992; T Permadi, 2017). Salah satu naskah kuno yaitu naskah Sunda yang merupakan salah satu dari sekian banyak naskah yang dimiliki Indonesia. Naskah Sunda adalah naskah yang penulisan dan penyusunannya dilakukan di daerah Sunda, serta naskah yang berisi cerita tentang wilayah Sunda maupun orang Sunda. Aksara yang digunakan dalam naskah Sunda di 
Erni Siti Nuraeni, Yeni Wijayanti, Dewi Ratih

Perilaku Hulun (Karma Ning Hulun) dalam Naskah Sanghyang Siksa Kandang Karesian

antaranya aksara Sunda Kuna, aksara Pegon, aksara Jawa, dan Latin (Ekajati, 1988; J. Sundari 2016).

Dalam berbagai macam naskah Sunda kuno terdapat salah satu naskah yang menjelaskan tentang perilaku rakyat Sunda pada zaman pemerintahan Pakuan Padjajaran yang akan menjadi pembahasan peneliti, yaitu naskah Sanghyang Siksa kandang Karesian. Naskah Sanghyang Siksakandang Karesian termasuk ke dalam unsur kebudayaan yaitu sistem pengetahuan, karena mencakup pengetahuan manusia tentang berbagai unsur yang digunakan dalam kehidupannya dan di dalam naskah tertulis bentuk bahasa yang digunakan pada zaman itu. Sanghyang Siksa Kandang Karesian adalah naskah Sunda kuno tertua yang mencantumkan tahun penulisannya yaitu 1440 Saka (1518 Masehi), sehingga naskah ini diperkirakan ditulis dalam masa pemerintahan Sri Baduga Maharaja penguasa Pakuan Pajajaran (1482-1521 M). Isinya memberikan gambaran tentang pedoman moral umum untuk kehidupan bermasyarakat pada masa itu, termasuk berbagai ilmu yang harus dikuasai sebagai bekal kehidupan praktis sehari-hari. Penuturannya berpijak pada kehidupan di dunia dalam negara. Aturan yang terdapat dalam Sanghyang Siksa Kandang Karesian terdiri atas tiga bagian utama, yaitu 1) pembuka yang menjelaskan sepuluh aturan (dasa kreta dan dasa prebakti), 2) perilaku hulun (karma ning hulun) terhadap raja di dalam negara, 3) pelengkap perbuatan (pangimbuh ning twah). Tulisan ini bertujuan untuk menguraikan garis besar hukumhukum yang terdapat naskah Sanghyang Siksa Kandang Karesian (Novi Nurazizah, 2016; Nurwansah, 2017; Ilham Nurwansyah, 2019;).

Dari uraian di atas, maka terlihat bagaimana seseorang diharuskan bersikap, berprilaku dalam kehidupan pada masa sekarang. Jika kita belajar dari sejarah, konsep seperti ini sudah ada. Cara kira menghadap atau berperilaku pada orang memiliki aturan sendiri. Pada perilaku hulun (karma ning hulun) dalam naskah Sanghyang Siksa KandangKaresian merupakan bagian dari gambaran perilaku masyarakat pada masa Pakuan Padjajaran, pembahasan difokuskan mengenai perilaku seorang hulun terhadap seorang raja. Berdasarkan hal tersebut, tujuan penelitian untuk menggali dan mengkaji perilaku menurut naskah Sanghyang Siksakandang Karesian.

\section{Metode}

Penelitian ini menggunakan pendekatan kualitatif dengan metode historis atau metode sejarah. Metode sejarah tediri dari tahap Heuristik (mencari, menemukan dan pengumpulan sumber), Kritik (menguji data), Interpretasi (penafsiran) dan Historiografi (Penulisan Sejarah). Tahap pengumpulan data (heuristik) yang dilakukan peneliti adalah menggunakan teknik studi literatur yang dilakukan dengan membaca literatur, mencatat dan mengolah bahan penelitian, dengan literatur peneliti akan mendapatkan data-data 
yang berhubungan dengan masalah penelitian. Tahap pengujian data (kritik) terbagi menjadi kritik intern dan kritik ekstern. Kritik intern untuk menguji kredibilitas sumber dan kritik ekstern untuk menguji keautentikan sumber, setelah data teruji dan diverifikasi maka akan menjadi suatu fakta sejarah. Fakta-fakta sejarah tersebut kemudian diinterpretasikan (ditafsirkan) dan dirangkai dalam penulisan sejarah yang dinamakan historiografi.

\section{Hasil dan Pembahasan}

Berdasarkan naskah Sanghyang Siksakandang Karesian terdapat beberapa perilaku hulun terhadap raja di dalam negara antara lain:perilaku menghadap kepada raja. Seorang hulun harus menjunjung tinggi kesetiaan dan pengabdiannya terhadap raja (penguasa). Jika hulun sungguh-sungguh setia dan mengabdikan dirinya pada raja, maka dosanya akan terhapus termasuk dosa yang bersumber dari ketidakmampuan memelihara dasa indera. Perintah raja bersifat mutlak, apapun yang diperintahkannya seorang hulun harus selalu siap menjalakannya. Tidak ada pengecualian karena raja adalah pemilik kekuasaan tertinggi yang harus dipatuhi dan ditaati, tidak boleh dibantah. Hulun harus mengutamakan kepentingan raja terlebih dahulu daripada kepentingan pribadinya, apabila ia lebih mengutamakan kepentingan peribadinya itu adalah suatu kesalahan dan mendatangkan masalah bagi dirinya.

Perilaku yang baik bagi orang banyak, pada bagian ini dijelaskan bahwa perilaku manusia yang akan berguna bagi orang banyak adalah yang menuruti ajaran Sanghyang Siksa Kandang Karesian, setiap hulun diperintahkan untuk selalu hati-hati terhadap pancagati agar terhindar dari kesengsaraan (Yayat Suharyat, 2009; Nurwansah, 2017). Pancagati merupakan 5 (lima) penyakit seperti serakah, kebodohan, kejahatan, takabur, dan keangkuhan. Serta jangan memiliki sifat khianat, arti kata khianat dalam konteks adalah tidak boleh menipu diri sendiri maupun orang banyak. serta tidak boleh memiliki sifat culas (Danasasmita et al., 1987). Hulun juga tidak boleh menginap di rumah penguasa atau raja secara terus-menerus atau dalam jangka waktu yang lama.

Perilaku dihadapan menak Hulun harus duduk bersila dan tangannya menyembah jika sedang berbicara dengan menak, majikan, pemilik tanah, kedua orang tua, serta wanita larangan juga harus berhati-hati. Wanita larangan memiliki arti seorang wanita (gadis) yang telah bertunangan dan telan menerima panglarang (tanda pinangan). Makna seorang hulun harus berhati-hati dalam berbicara yaitu harus bersikap hormat, sopan, serta tidak boleh berbicara yang tidak baik (Danasasmita et al., 1987).

Perilaku ketika memegang rahasia, ketika seorang hulun diberikan kepercayaan untuk memegang suatu rahasia, maka ia harus melaksanakannya dengan baik. Sehingga 
Erni Siti Nuraeni, Yeni Wijayanti, Dewi Ratih

Perilaku Hulun (Karma Ning Hulun) dalam Naskah Sanghyang Siksa Kandang Karesian

ia tidak boleh memberitahukan rahasia itu kepada siapapun bahkan jangan sampai memberi informasi yang salah terhadap sebuah rahasia. Jika hal itu terjadi, maka akan sia-sia segala hasil ia bertapa, jasa-jasa leluhur dan hasil jerih payahnya akan hilang, serta akan mendapatkan kesengsaraan, kesengsaraan yang akan didapatkan yaitu tidak akan hidup tenang, penuh dengan masalah, jasa-jasa leluhurnya tidak akan pernah ia rasakan, serta hasil jerih payah selama hidupnya akan sia-sia dan akan hilang, bahkan akan diasingkan dari daerah tersebut (Novi Nurazizah, 2016; Nurwansah, 2017). Seorang hulun jika diberi amanah oleh raja sebuah rahasia, baik rahasia negara maupun rahasia raja itu sendiri, ia harus bisa menjaga rahasia itu dengan sangat baik dan jangan sampai ia menyebarkannya pada orang lain. Apabila rahasia itu tersebar, maka usaha dalam hidupnya, kebaikannya akan hilang serta hidup dalam kesengsaraan, dapat merusak hubungan persaudaraan, kekerabatan, mengkhianati amanat dan melanggar janji, tentunya apabila itu terjadi ia tidak akan hidup tenang di dunia. Hulun juga tidak boleh menunjukkan roman muka yang masam atau merasa tidak senang kepada raja, karena itu namanya pamali (pantangan/larangan).

Perilaku hulun yang tidak setia, pada bagian ini, memaparkan praduga buruk dari seorang hulun terhadap raja yang mengakibatkannya menderita sakit dan menjadi lemah. Dengan demikian ia menyatakan tidak akan setia kepada raja. Padahal raja telah menyebutkan jaminan bagi siapapun yang setia kepadanya. Tampaklah sikap seorang raja terhadap rakyatnya dengan kondisi demikian, yaitu dengan memberikan ia kesempatan untuk belajar setia kepadanya. Namun tentunya dengan syarat jangan enggan diperintah dan tidak boleh mengeluh (Novi Nurazizah, 2016; Nurwansah, 2017; Ilham Nurwansyah, 2019). Hulun tidak boleh sering mengeluh, merasa kecewa dan jangan tidak ingin diperintah. Jangan pula merasa iri dengki terhadap sesama abdi raja, perasaan iri dan dengki hanya akan menyakiti dirinya sendiri, menjadi tidak akur dengan sesama hulun. Kesetiaan dan pengabdiannya harus dilakukan dengan senang hati dan ikhlas. Apabila mengabdi dengan sungguh-sunggu maka raja pun akan membalas dengan kebaikan pula, karena perbuatan baik akan kembali baik pada dirinya sendiri begitupun sebaliknya.

Perilaku ketika melihat orang yang mendapat pujian, hulun tidak boleh sampai kesetiaannya berkurang terhadap raja. Ketika seorang hulun melihat orang lain mendapatkan pujian, mendapatkan selir, dan melihat orang yang disayangi raja, ia harus tetap teguh pada kesetiaan dan pengabdiannya. Hulun tidak boleh iri dengan hal tersebut, karena pasti akan merasakan sakit hati dan berkurangnya kesetiaan terhdap raja. Rasa sakit hati itu akan sulit diobati dengan apapun karena itu merupakan penyakit hati, lebih baik menenangkan diri dengan cara memperbaiki pengabdian terhadap raja, karena apabila seorang hulun merasa iri, maka Hal ini tidak dibenarkan oleh ajaran Sanghyang 
Siksa Kandang Karesian. Pada ajaran Islam, hati seseorang bisa menjadi tempat berkumpulnya kebaikan maupun keburukan. Jika yang berada di dalam hatinya merupakan hal-hal buruk, maka hal tersebut bisa disebut dengan penyakit hati. Penyakit hati adalah penyakit yang mengganggu hati dan perasaan manusia. Sehingga dapat berpengaruh buruk pada perilaku serta perbuatan seseorang. Salah satu penyakit hati yang dapat berpengaruh pada manusia ialah dengki (Rokhmah et al., 2018; Ila Nurlaila Hidayat \& Witrin Gamayanti, 2020).

Perilaku terpilih menjadi anggota pasukan, hulun harus benar-benar melaksanakan tugasnya dengan disiplin, patuh dan jangan sampai mendapatkan kemarahan dari seorang nangganan. Nangganan memiliki arti membariskan atau pemimpin barisan yang kedudukannya setingkat di bawah mangkubumi. Namun, jika mendapatkan kemarahan pun ia harus tetap berbakti pada seorang tanda yang merupakan pejabat tinggi negara (Danasasmita et al., 1987). Hulun harus sungguhsungguh menjadi anggota pasukan kerajaan, pasukan dalam konteks ini kemungkinan merupakan pasukan yang dilatih untuk berperang, dengan demikian hulun harus memiliki fisik yang kuat dalam menjalani latihan dan melaksanakan perang membela kerajaan, serta menuruti perintah dari seorang pemimpin pasukan (nangganan) karena ia merupakan pejabat tinggi negara yang bertugas mengatur pasukan kerajaan. Pasukan perang kerajaan yang diketahui salah satunya adalah puragabaya.

Perilaku ketika mendapat perintah, harus tetap menerapkan ajaran Sanghyang Siksa Kandang Karesian agar tetap setia dalam melaksanakan tugas dari raja. Ketika seorang hulun diperintahkan ke arah mana pun, maka ia harus selalu menjalankan catur yatna. Catur yatna yaitu empat kewaspadaan, diantaranya ia tidak boleh siwok ca(n)té, simur canté, simar canté, darma canté (Nurwansah, 2017; Ilham Nurwansyah, 2019). Catur yatna atau empat kewaspadaan yang meliputi siwok ca(n)te yaitu tidak boleh sampai tergoda oleh makan dan minum sehingga mengabaikan tugasnya. Simur ca(n)te adalah mengikuti perbuatan buruk dan terlibat dengan orang yang melakukan pencurian. Simar $c a(n)$ te yaitu mengambil dagangan milik orang lain tanpa izin pemilik, dan darma ca(n)te yaitu tidak boleh membantu orang-orang yang membenci raja, sekalipun orang yang dibenci raja tersebut adalah kerabat, keluarga maupun saudara hulun itu sendiri.

Terdapat beberapa peraturan yang harus dipatuhi seorang hulun ketika berjalan di hutan antara lain: 1) tidak boleh sembarang memetik sayur di ladang kecil dan kebun milik orang lain. Jika hal itu dilakukan, maka segala amal baik nya akan sia-sia. 2) tidak boleh merubah atau menghilangkan batas kebun di hutan, tidak boleh mengambil kayu yang ditandai tali, pohon buah yang ditandai ranting, kayu bakar yang disandarkan, cendawan yang ditutupi, sarang tiwuan, odeng, lebah, engang, ulat kayu, parakan atau 
Erni Siti Nuraeni, Yeni Wijayanti, Dewi Ratih

Perilaku Hulun (Karma Ning Hulun) dalam Naskah Sanghyang Siksa Kandang Karesian

apapun yang telah diberi tanda tali sebagai tanda kepemilikan. 3) serta tidak boleh menurunkan sadapan milik orang lain, karena jika dilakukan akan menjadi sumber dosa, dasar kenistaan dan noda (Nurwansah, 2017; Ilham Nurwansyah, 2019; Novi Nurazizah, 2016).Perilaku untuk menuruti tohaan (pangeran/raja). Apapun yang diperintahkan oleh raja, harus dilaksanakan dengan baik, dengan senang hati dan jangan sampai membuat raja merasa kecewa. Hulun harus mengikuti segala yang diarahkan oleh raja termasuk dalam perbuatan. Salah satunya ketika raja marah terhadap sesuatu, maka hulun harus ikut merasakan kemarahan raja. Begitupula ketika raja memuji, hulun juga harus ikut memuji. Hal demikian diibaratkan seorang hulun itu adalah bayangan dari sang raja, apapun gerak dan yang dilakukan oleh raja harus dituruti dan dipatuhi dengan baik. Perilaku ketika berjalan di hutan.

Perilaku ketika bertemu dengan pejabat negara, dalam pasowanan ini raja membicarakan atau menanyakan perihal kelancaran pemerintahan, kesulitan-kesulitan yang dihadapi dan juga merembukkan rencana-rencana dalam mengatur pemerintahan serta kegiatan-kegiataan raja. Dari Pasowanan ini raja dapat mengukur kadar kesetiaan bawahannya, baik dari daerah maupun dari orang-orang yang ada di sekitar kraton (Yasmis, 2008; Istiana Adianti, 2009). Kemungkinan acara pertemuan tersebut dilaksanakan di keraton kerajaan, atau bahkan di bale pertemuan khusus dengan para bawahan raja maupun pejabat-pejabat negara lain yang menjadi tamunya. Hulun harus tetap menjaga etika dengan segera memakai pakaian yang rapih dan sopan, Posisi hulun ketika bertemu dengan pejabat negara dalam acara pertemuan, ia harus duduk bersila dengan tangan seraya menyembah berdasarkan ya g telah dijelaskan pada perilaku hulun sebelumnya, sedangkan apabila bertemu pejabat negara di jalan, ia harus selalu berada di sebalah kirinya seraya berjongkok, terutama apabila bertemu dan berkomunikasi dengan guru loka (guru sang raja).

Perilaku terhadap wanita larangan. Naskah Sanghyang Siksakandang Karesian mengatur perilaku seorang hulun khususnya laki-laki terhadap seorang wanita larangan. Pada pembahasan sebelumnya telah dijelaskan bahwa wanita larangan adalah wanita (gadis) yang telah bertunangan dan telah menerima panglarang (tanda pinangan). Pertunangan berasal dari kata tunang; bertunangan yang mempunyai arti bersepakat (biasanya diumumkan secara resmi atau dinyatakan di hadapan orang banyak) menjadi suami istri, dengan kata lain telah melakukan pertunangan (permintaan hendak memperistri) (Sugiono \& Maryani, 2008; Iwan Kuswandi, 2018). Seorang hulun dalam konteks ini dilihat dari sudat pandang seorang laki-laki, dimana pada ajaran ini terdapat larangan bagi seorang laki-laki untuk berdekatan dengan wanita larangan, tidak boleh sedikit pun menyentuhnya, tidak boleh berjalan bersama, duduk bersama, tidak boleh berada disuatu tempat yang sama berdua dengan wanita larangan tanpa ada yang 
mendampinginya. Hal demikian bertujuan agar tidak terjadi hal-hal yang diinginkan dan mencegah kesalahpahaman, menghindari berbagai macam godaan, karena secara etika, wanita yang sudah bertunangan sudah diikat oleh laki-laki yang akan menikahinya.

Perilaku penghormatan terhadap orang lain, yaitu seorang tidak boleh bahkan dilarang menyahut orang batuk, mendehem, membuang dahak, menyahut ibu-ibu yang menyanyi ( Wibowo, 2015; Nurwansah, 2017; Ngadat, 2018). Seorang hulun tidak boleh menyahut orang yang batuk, tidak boleh mendehem kepada orang lain, tidak boleh mengeluarkan dahak di depan orang banyak, tidak boleh menyahut ibu-ibu yang sedang menyanyi, karena hal demikian adalah perbuatan yang tidak sopan dan tidak menghormati sesama dengan tidak memandang kaya, miskin, terpandang, baik, buruk dan sebagainya. Tentunya sikap hormat itu sangat penting bagi orang Sunda. Larangan lain untuk seorang hulun sebagai bentuk penghormatan yaitu dilarang bersandar pada tiang atau duduk di batu bekas orang suci. Bentuk penghormatan yang lainnya yaitu seorang hulun tidak boleh satu tempat menginap, satu tempat tinggal ataupun sebalai dengan orang suci serta dengan wanita larangan (wanita yang sudah bertunangan).

Perilaku ketika kedatangan petugas negara seperti kedatangan sanak keluarga, saudara, adik, kakak, anak, teman sejawat, dan keponakan. Namun, apabila dari hulun itu timbul rasa sayang terhadap mereka, maka ia harus menyediakan makanan, minuman, selimut dan kain yang ia miliki. Hal demikian dianggap persembahan puja dan berlindung kepada hiyang dan dewata (Danasasmita et al., 1987). Berdasarkan hal tersebut dijelaskan bahwa ketika hulun kedatangan tamu seperti pejabat negara yang akan memungut pajak, maka ia harus menerimanya dengan baik, menyambutnya dengan sikap yang ramah, harus menunjukkan perangai yang baik, rasa senang dan menganggap kedatangan mereka seperti kedatangan saudara, kerabat maupun keluarga sendiri. Kemudian mempersilahkannya untuk duduk dan menyuguhkan makanan dan minuman sesuai dengan kadar kemampuan sang pemilik rumah, dan tanpa memaksakan diri.

Perilaku ketika mendapatkan perintah bekerja di ladang/sawah. Perilaku seorang hulun ketika mendapat perintah dari penguasa (raja) untuk bekerja di ladang, sawah maupun serang (sawah yang padinya digunakan untuk kepentingan upacara umum atau sawah milik pejabat), pekerjaan yang harus dilakukan seperti mengukuhkan sungai, menggali saluran untuk air, mengandangkan ternak, memasang ranjau tajam, membendung sebagian alur sungai untuk menangkap ikan, menjala ikan, menarik jaring, memasang jaring, menangguk ikan, merentang jaring dan semua pekerjaan untuk kepentingan raja. Pekerjaan itu semua harus dilakukan dengan tulus dan sepenuh hati, tidak boleh kesal, marah-marah, serta tidak boleh munafik (Nurwansah, 2017; Ilham 
Erni Siti Nuraeni, Yeni Wijayanti, Dewi Ratih

Perilaku Hulun (Karma Ning Hulun) dalam Naskah Sanghyang Siksa Kandang Karesian

Nurwansyah, 2019). Berdasarkan hal tersebut dijelaskan bahwa hulunharus melaksanakannya dengan senang hati dan ikhlas. Pekerjaan tersebut untuk kepentingan raja serta rakyatnya sendiri, sebagi seorang hulun sudah menjadi tugasnya untuk taat dan patuh terhadap perintah raja, karena ia sudah mengabdikan dirinya pada raja.

Namun bila kita pulang ke kota, jangan berak di pinggir jalan atau di pinggir rumah di ujung bagian yang tak berumput, agar tidak tercium oleh menak dan gusti. Timbuni tungku yang berlubang-lubang supaya tidk dikutuk dan disalahkan ibu-bapak dan perguruan, disesali oleh orang-orang tua karena perbuatan kita yang ceroboh. Namun kalau menurut sanghyang siksa, berak harus tujuh langkah dari jalan, kencing harus tiga langkah dari jalan. Pasti tidak akan dimarahi orang lain karena kita mengetahui perbuatan yang terlarang. Kalau dikerjakan akan mendatangakan sedih, yang terlarang itu dapat mengakibatkan kematian; dan (dalam kota itu) perhatikanlah tempat hukuman (?), ujung kayu penjepit tangan hukuman, mungkin pemandian keraton, kandang larangan, rumah larangan (Danasasmita et al., 1987; Novi Nurarizah, 2016; Ilham Nurwansyah, 2019). Terjemahan naskah tersebut menjelaskan ketikahulun hendak pergi ke suatu tempat, dan di perjalanan tiba-tiba ia merasakan ingin buang hajat. Tata cara buang hajat ketika berada di perjalanan telah diatur, hulun tidak boleh buang hajat di sembarangan tempat karena ditakutkan tercium aroma tidak sedap oleh orang lain. Jika ia buang hajat sembarangan maka perbuatannya tersebut sangat terlarang, yang apabila dikerjakan akan mendapatkan hukuman seperti pasung, pengasingaan, bahkan hukum kurungan. Untuk tata cara buang air kecil ketika berada di jalan, jaraknya harus tiga langkah dari jalan. Sedangkan untuk buang air besar, jaraknya tujuh langkah dari jalan.

Perilaku ketika memintas jalan. Ketika seorang hulun bertemu dengan rombongan raja yang sedang berkumpul dan bercengkrama di jalan, kemudian hendak memintas jalan, ia tidak boleh menghampiri bahkan tidak boleh melewati rombongan tersebut karena hal itu merupakan perbuatan dosa (Danasasmita et al., 1987; Ilham Nurwansyah, 2019). Berdasarkan jutipaan tersebut dijelaskann bahwa ketika hulunsedang berjalan kemudian bertemu dengan rombongan raja yang sedang berkumpul, ia tidak boleh sembarangan menghampiri dan melewati rombongan tersebut. Jika etika tersebut tidak dilakukan, maka hulun tersebut telah melakukan perbuatan dosa dan melanggar ajaran Sanghyang Siksa Kandang Karesian.

Perilaku ketika masuk ke dalem (keraton), ada beberapa hal yang harus perhatikan antara lain jangan sampai melanggar, mendorong, mengganggu atau memutus jajaran orang-orang yang sedang duduk. Apabila ia ingin duduk maka tidak boleh salah menghadap dan bersila yang baik. Kemudian jika ada seorang raja yang mengajak berbicara, ia harus benar-benar hati-hati dalam ucapan dan mengatakan kata-kata yang layak agar sang raja senang terhadapnya (Nurwansah, 2017). Hulun harus bersikap ramah 
dengan menunjukkan sikap hormat, melihat dengan baik disekeliling keraton terdapat siapa saja, jangan sampai ia melanggar aturan, tidak boleh melakukan perbuatan yang dapat mengganggu orang-orang yang berada di dalam keraton, jika hendak duduk maka tidak boleh memutus jajaran orang lain yang sedang duduk pula (mencari tempat yang kosong), ketika sudah mendapatkan tempat duduk maka ia harus duduk dengan bersila. Etika duduk pun seorang hulun harus selalu menghadap ke arah raja, apabila raja mengajaknya berbicara ia harus benar-benar memperhatikan perkataannya terhadap raja (tidak boleh salah ucap) dan menggunakan bahasa yang baik dan layak supaya raja senang terhadapnya.

Perilaku ketika dimarahi raja. Jika ada di antara kita yang dipuji, cekatan, terampil, penuh keutamaan, cermat, teliti, rajin, tekun, setia terhadap tugas bagi raja, yang demikian itu patut ditiru perbuatan dan tabiatnya, pasti kita pun akan dipuji (Atja \& Danasasmita, 1981). Berdasarkan kutipan tersebut, apabila terdapat salah satu diantara hulun yang menyebabkan raja marah, hulun yang lain tidak boleh menirunya jika tidak ingin mengalami nasib yang sama. Justru ia harus menjadikan hal tersebut sebagai pelajaran dan perbaikan untuk dirinya sendiri, tidak boleh mengikuti perilaku yang tidak baik untuk ditiru. Sebagai perbandingannya, ketika orang lain pergi ke hutan dan menginjak duri lalu kita ikut menginjaknya, pasti akan merasakan sakit yang sama. Apabila diantara hulun ada yang mendapatkan pujian dari raja, dengan alasan karena dirinya melaksanakan perintah raja dengan cepat, penuh keterampilan, penuh keutamaan, cermat, sangat teliti, rajin dan tekun, dan yang paling utama adalah ia sangat setia pada perintah yang diberikan oleh raja. Perilaku demikianlah yang baik untuk ditiru oleh hulun lainnya, karena jika perilaku itu ditiru akan mendapatkan pujian juga dari raja. Perilaku teladan manusia yang patut ditiru, tirulah seluruhnya karena yang demikian itu disebut manusia utama. Bila ada orang yang buruk penampilannya, pandir tingkahnya, tetapi baik perbuatannya, yang demikian itu jangan ditiru tingkahnya, perhatikan penampilannya, dan tirulah perbuatannya. Bila ada orang yang buruk penampilannya, pandir tingkatnya, dan buruk pula perbuatannya, yang demikian itu noda dunia, menjadi pengganti (tumbal) kita seluruh dunia, namanya kebusukan (diantara manusia. Itu semua patut diingat, sengsara dan bahagia, buruk dan baik, tergantung pada guru (Danasasmita et al., 1987; Ilham Nurwansyah, 2019; Novi Nurarizah, 2016)".Perilaku teladan manusia yang baik untuk ditiru oleh hulun yaitu dengan hanya meniru perilaku atau perbuatan yang baik dari diri seseorang atau dengan kata lain hanya meniru sisi baiknya. Misalnya ada orang yang baik dari segi penampilan, perilaku dan perbuatannya maka hulun harus bisa meniru semuanya karena itu merupakan perilaku yang baik. Kemudian jika ada orang yang kurang baik dari segi 
Erni Siti Nuraeni, Yeni Wijayanti, Dewi Ratih

Perilaku Hulun (Karma Ning Hulun) dalam Naskah Sanghyang Siksa Kandang Karesian

penampilan, kurang baik perilakunya tetapi perbuatannya baik, maka hulun harus meniru perbuatannya yang baik. Jika ada orang yang buruk penampilannya, buruk perilakunya, buruk pula perbuatannya, maka hulun tidak boleh meniru semuanya karena itu merupakan hal yang buruk dan merupakan sumber noda dunia yang menyebabkan kesengsaraan dalam kehidupan manusia.

Perilaku setelah melaksanakan kewajiban dan pekerjaan. Pada dasarnya bekerja itu bermakna menanam budi baik, diiringi niat sebagai pengabdian yang diperlihatkan melalui perilaku, ucap, sikap, dan perbuatan. Rakyat dan bawahan hendaknya bersikap memiliki rasa takut, segan dan hormat (Atja \& Danasasmita, 1981).Ketika seorang hulun telah menyelesaikan tugas dan pekerjaan, ia harus memeriksa kembali hasil pekerjannya itu. Memeriksa kembali apakah sudah seseuai dengan yang diperintahkan atau masih ada kekurangan, meninjau kembali mana yang sudah baik. Memeriksa hasil pekerjaan ini bisa dikatakan jika sekarang itu dengan evaluasi atau mengevaluasi.

Perilaku ketika mendapat pujian, maka ia tidak boleh larut dalam kesenangan karena dipuji dan harus bersikap rendah hati, kembali memuji terhadap orang yang memberikan pujian padanya. Jika dirinya senang dipuji, maka ia sama seperti peribahasa galah panjang disambung ranting (belalai). Akibat dari rasa senang dipuji itu dapat menjadikannya takabur karena sudah merasa dirinya sudah cukup (Nurwansah, 2017; Ilham Nurwansyah, 2019; Novi Nurarizah, 2016). Hulun harus tetap rendah hati, tidak boleh terlalu bangga dan menjadikan pujian itu sebagai motivasi untuk meningkatkan kesetiaan dan pengabdiannya kepada sang raja. Hal itu lebih baik dilakukan daripada menjadi sombong dan angkuh karena pujian itu, tidak boleh merasa sudah cukup puas dengan apa yang telah dicapai.

Perilaku ketika ada yang mencela. "Begitulah kalau ada yang mencela (mengeritik) kepada kita, terimalah kritik orang lain itu. Yang demikian itu ibarat galah sodok dipotong runcing. Ibarat kita sedang dekil, celaan itu bagaikan air pemandian; ibarat kita sedang menderita kekeringan kulit, bagaikan datang orang yang meminyaki; ibarat kita sedang lapar, bagaikan datang yang memberi nasi; ibarat kita sedang dahaga, bagaikan datang yang mengantarkan minuman; ibarat kita sedang kesal hati, bagaikan datang orang yang memberi sirih pinang. Itulah yang disebut panca parisuda (lima penawar); ibarat galah sodok diperpendek (Danasasmita et al., 1987; Ilham Nurwansyah, 2019)". Ketika ada yang mencela hulunharus bisa menerima dengan hati yang lapang. Seperti halnya pada dengan menerima pujian sebagai motivasi untuk meningkatkan kinerja sang hulun, celaan atau kritikan juga harus ia jadikan sebagai motivasi untuk memperbaiki kinerjanya. Celaan ini terdapat Panca Parisuda (lima penawar) yang dapat menenangkan hati seorang hulun. Lima penawar itu menyebutkan bahwa celaan itu diibaratkan air yang dapatkan membersihkan kita ketika sedang dekil, ibaratkan sedang merasakan penyakit 
kulit lalu datang orang yang mengobati, ibarat kita sedang lapat lalu datang orang memberi makanan, ketika kita sedang merasa haus lalu datang orang yang memberi minuman dan ketika sedang merasakan kesal datang orang yang memberikan ketenangan. Demikianlah lima penawar untuk orang yang mendapatkan celaan, hakikatnya celaan itu tidak selalu memberikan dampak yang negatif, tetapi juga dapat memberikan dampak yang positif yaitu sebagai bahan perbaikan untuk lebih laik lagi.

Perilaku ketika mendapat kebahagiaan. "Bila kita merasa bahagia, ibarat padi berat isi, pasti sejahteralah orang banyak, karena bertemu dengan sumber kesenangan dan kenikmatan, (yaitu) tahan celaan dan mengambil (memperhatikan) nasihat orang lain. Bila sedang sibuk tundalah sementara, (lebih-lebih) bila sedang tidak ada pekerjaan, untuk menjenguk ibu-bapak. Itulah yang disebut manusia sejati; yang disebut keutamaan tertinggi; ibarat dewa berwujud manusia namanya; berperibadi sempurna, benih kebajikan dan pohon kebenaran (Danasasmita et al., 1987; Yayat Suharyat, 2009). Ketika seorang hulun mendapatkan rasa bahagia, karena tidak memperdulikan celaan (kritikan) dan lebih memilih mendengarkan nasihat dari orang lain upaya memberikan ketenangan dari celaan tersebut. Upaya agar seorang hulun merasa bahagia juga dapat dilakukan dengan menjenguk orang tua nya dikala sedang tidak ada pekerjaan. Perilaku tersebut lebih baik dilakukan karena cerminan dari manusia sejati, memiliki keutamaan, memiliki peribadi yang sempurna serta manusia yang bijaksana.

Demikianlah pembahasan mengenai perilaku hulun (karma ning hulun) terhadap raja di dalam negara. Pada naskah sanghyang siksa kandang karesian ini terdapat banyak perilaku yang dapat di contoh oleh masyarakat, khususnya perilaku sebagai rakyat terhadap pemimpin dan secara umum perilaku terhadap orang banyak dalam kehidupan sehari-hari. Kndisi seperti itu bisa kita gunakan dalam kehidupan saat sekarang, sebagai warganegara Indonesia, bagaimana kita bersikap pada seseorang dan menjelankan komunikasi dengan baik.

\section{Simpulan}

Aturan yang terdapat dalam Sanghyang Siksa Kandang Karesian terdiri atas tiga bagian utama, yaitu 1) pembuka yang menjelaskan sepuluh aturan (dasa kreta \&dasa prebakti), 2) perilaku hulun (karma ning hulun) terhadap raja di dalam negara, 3) pelengkap perbuatan (pangimbuh ning twah). Seorang hulun memiliki beberapa perilaku yang harus dilaksanakan oleh antara lain ketika mengahadap kepada raja, perilaku yang baik bagi orang banyak, ketika di hadapan menak, ketika memegang rahasia, aturan perilaku hulun yang tidak setia, ketika melihat orang yang mendapat pujian, ketika terpilih menjadi anggota pasukan kerajaan, ketika mendapat perintah dari raja, ketika menuruti 
Erni Siti Nuraeni, Yeni Wijayanti, Dewi Ratih

Perilaku Hulun (Karma Ning Hulun) dalam Naskah Sanghyang Siksa Kandang Karesian

tohaan, ketika berjalan di hutan, ketika bertemu dengan pejabat negara, perilaku terhadap wanita larangan, penghormatan terhadap orang lain, ketika kedatangan petugas negara, ketika mendapatkan perintah bekerja di ladang/sawah, ketika buang air, ketika memintas jalan, ketika masuk ke dalem (keraton), ketika dimarahi raja, perilaku teladan manusia yang patut ditiru, setelah melaksanakan kewajiban dan pekerjaan, ketika mendapat pujian, ketika ada yang mencela, dan ketika mendapat kebahagiaan.

\section{Daftar Rujukan}

Atja, \& Danasasmita, S. (1981). Sanghyang Siksakanda Ng Karesian. Proyek Pengembangan Permuseuman Jawa Barat.

Ayatrohaedi. (2002). Kerajaan Sunda Menjelang Keruntuhannya. FSUI.

Baried, S. B., Siti Chamamah, S., Sawoe, Sutrisno, S., \& Moh, S. (1985). Pengantar Teori Filologi (N. Hasjim (ed.); 1 Ed). Pusat Pembinan dan Pengembangan Bahasa Departemen Pendidikan dan Kebudayaan.

Danasasmita, S., Rohaedi, A., Wartini, T., \& Ahmad Darsa, U. (1987). Sewaka darma (Kropak 408); Sanghyang siksakandang karesian (Kropak 630); Amanat Galunggung (Kropak 632): transkripsi dan terjemahan. Bagian Proyek Penelitian dan Pengkajian Kebudayaan Sunda (Sundanologi) Direktorat Jenderal Kebudayaan Depdikbud.

Dasrun Hidayat, Hanny Hafiar. 2019. Nilai-nilai Budaya Soméah Pada Perilaku Komunikasi Masyarakat Suku Sunda. Jurnal Kajian Komunikasi, 7(1).

Departemen Pendidikan dan Kebudayaan. 1980. Transkrips Naskah-naskah Kuno: Babad Mataram. Kebudayaan Pusat Penelitian Sejarah dan Budaya: Balai Penelitian Sejarah danBudaya.

Ekajati, E. S. (1988). Naskah Sunda: Inventarisasi dan Pencatatan. Kerja sama Lembaga Penelitian Universitas Padjadjaran.

Ila Nurlaila Hidayat, Witrin Gamayanti. 2020. Dengki, Bersyukur dan Kualitas Hidup Orang yang Mengalami Psikosomatik. Jurnal Ilmiah Psikologi Pysmpathic, 7(1)

Ilham Nurwansyah. 2019. Naskah Lontar Sunda Kuna Sanghyang Siksa Kandang Karesian. Jumantra. 
Istiana Adianti. 2019. Tipologi Tata Ruang Rumah Bangsawan didalam Baluwarti Kraton Yogyakarta. Jurnal Arsitektur Pendapa, 2(1).

Iwan Kuswandi. 2018. Mitos Sangkal Dalam Tradisi Pertunangan Dini Di Madura. Prosiding Semnas PPM, 1(1).

Jenie Sundari. 2016. Melestarikan Aksara Sunda Dengan Aplikasi Multimedia. Jurnal Sains dan Manajemen, 4(2).

Karlina, N., Yunus, A., Rosyadi, \& Ganda, Y. (1992). Serat siksa kanda karesian. Departemen Pendidikan dan Kebudayaan, Direktorat Jenderal Kebudayaan.

Ngadat. 2018. Akulturasi Nilai-Nilai Budaya Dan Ajaran Buddha Sebagai Bentuk Perilaku Perbuatan Benar Masyarakat Umat Buddha Di Desa Prigi Kecamatan Kedung Jati Kabupaten Grobogan Jawa Tengah. Jurnal Pendidikan, Sains, Sosial dan Agama, 4(1).

Nurwansah, I. (2017). Hukum dalam Naskah Sunda Kuna Sanghyang Siksa Kandang Karesian. Manuskripta, 7(1), 31-61.

Nurazizah. 2016. Etika Sunda (Studi Naskah Sanghyang Siksa Kandang Karesian). Skripsi.

Rokhmah, A. F., Ilmu, P., Dan, A., Ushuluddin, F., Filsafat, D. A. N., Islam, U., \& Sunan, N. (2018). Dengki dalam perspektif al-quran korelasi dengan teori agresi.

Pien Supinah. 2006. Sawer: Komunikasi Simbolik pada Adat Tradisi Suku Sunda dalam Upacara Setelah Perkawinan. Mediator Jurnal Komunikasi, 7(1).

Sugiono, \& Maryani, Y. (2008). Kamus Bahasa Indonesia (p. 1826). Pusat Bahasa.

Tedi Permadi. 2017. Naskah Nusantara dan Berbagai Aspek yang Menyertainya. Arsip Repository UPI.

Wibowo. 2015. Kajian Simulasi Desain Rambu Informasi Keselamatan Di Tempat Wisata Pantai Parangtritis Berdasarkan Perilaku Budaya. Jurnal Eka Rupa, 3(1).

Yasmis, Y. (2008). Struktur Birokrasi Kerajaan Pajajaran Abad X-XI. Jurnal Sejarah Lontar, $5(1), 45-55$. 
Erni Siti Nuraeni, Yeni Wijayanti, Dewi Ratih

Perilaku Hulun (Karma Ning Hulun) dalam Naskah Sanghyang Siksa Kandang Karesian

Yayat Suharyat. 2009. Hubungan Antara Sikap, Minat dan Perilaku Manusia. Jurnal Region. 